\title{
DINÂMICA E SOCIABILIDADE EM FAMÍLIAS DE CLASSES POPULARES: HISTÓRIAS DE VIDA ${ }^{1}$
}

Marina Rezende Bazon ${ }^{2}$

\begin{abstract}
RESUMO: Este trabalho investiga histórias de vida de três famílias, cadastradas em programas sociais, cujos filhos encontravam-se abrigados em instituição, sob medida de proteção. O objetivo consistiu em identificar e analisar aspectos inerentes a suas dinâmicas e sociabilidade. A coleta de dados deu-se através da análise dos prontuários, entrevistas com profissional responsável pelo acompanhamento dos casos e com membros delas. Os dados foram organizados de modo a esboçar as trajetórias percorridas pelos grupos familiares tendo em vista o momento anterior e posterior ao abrigamento dos filhos. Os.resultados permitem afirmar que as três famílias pertencem às classes populares e que todas partem de um modelo nuclear. Ao longo das histórias, frente às inúmeras dificuldades materiais, verificar-se-ia a desagregação do grupo inicial com a recorrência a estratégias de sobrevivência bastante diversificadas, incluindo o abrigamento dos filhos.
\end{abstract}

Palavras Chaves: crianças/adolescentes em situação de risco; famílias de classes populares; dinâmica familiar;

\section{DYNAMICS AND SOCIABILITY IN POPULAR CLASSES FAMILIES: LIFE'S HISTORIES}

\begin{abstract}
This work investigates life's histories of three families that were making part of social programs whose kids were sheltered in a home care center, under protection measure. The goal was to identify and to analyze some inherent aspects of their dynamics and sociability. The data's collected was through institutional reports, interviews with the professional that followed the cases (a social worker) and informal interviews with the three families' members. The results allow affirm that the three families are from a low social status and they started following a nuclear model. In their histories, in front of several material difficulties, we verify the initial group desegregation and the use of survival strategies, including their children institutionalization.
\end{abstract}

Key words: children/adolescents at risk situation; low social class' family; dynamic family;

A concepção de infância tem se transformado ao longo da história, mudando tảmbém a visão que se tem de suas necessidades e dos serviços que devem ser oferecidos a ela. Neste final de milênio, fruto de uma postura mais humanista, a noção de que a criança, independentemente de sua posição na estrutura social, é um sujeito de direitos e uma pessoa em condição peculiar de desenvolvimento tem se firmado, estabelecendo os parâmetros iniciais para a elaboração e a implementação de políticas que a beneficiem (Barreira, Blanes \& Carvalho, 1992).

\footnotetext{
${ }^{1}$ Artigo recebido para publicação em novembro de 2000; aceito em fevereiro de 2001

2 Endereço para correspondência: Marina Rezende Bazon, Departamento de Psicologia e Educação, Faculdade de Filosofia, Ciências e Letras de Ribeirăo Preto-USP. Av Bandeirantes, 3900 - Cep. 14040-901 - Ribeirão Preto - SP - Brasil - E-mail: mbazon@ffclrp.usp.br
}

Dentre os direitos enunciados, destaca-se aquele que toda criança teria ao convívio familiar, formalizado juridicamente enquanto "o direito de ser criada e educada no seio de sua família e, excepcionalmente, em família substituta..." (Estatuto da Criança e do Adolescente, 1990).

Para além do aspecto legal, essa noção é central na discussão referente à atenção despendida à infância e juventude, pois a família é incumbida de zelar pela "efetivação dos (outros) direitos referentes à vida, à saúde, à alimentação, à educação, ao esporte, ao lazer, à profissionalização, à cultura, à dignidade, ao respeito, à liberdade..." (Szymanski, 1992, p.12). Assim, considerada responsável direta e imediata pela atualização dos direitos de seus filhos, a família, quando não cumpre sua função, tor-

Paidéia, FFCLRP-USP, Rib. Preto, jan/julho/2000. 
na-se alvo de intervenções e sanções.

Portanto, o atendimento à criança e ao adolescente em situação de risco pessoal e social passa, necessariamente, pela atenção dispensada às suas famílias através de políticas públicas específicas $\mathrm{e}$ programas promocionais $\mathrm{e}$ assistenciais, implementados por agentes especialmente preparados para o trabalho no contexto familiar.

Cumpre, contudo, lembrar que, na história da assistência social, o primeiro olhar lançado sobre as famílias pobres, cujos filhos eram considerados em situação de risco, ressaltou suas "deficiências", culpabilizando-as e isentando quase que completamente a sociedade e o Estado de qualquer responsabilidade pelos problemas que acometiam os jovens (Marcílio, 1998).

Essa postura orientou intervenções baseadas na institucionalização da infância e adolescência visando afastá-las da "origem de seus problemas", concorrendo para o esfacelamento dos vínculos familiares e comunitários e a assunção, pelo Estado, do "papel de padrasto", imbuído de toda a carga negativa que esta expressão pode suscitar (Guirado, 1980; Silva, 1997).

As críticas a essas ações insuflaram a luta pelos direitos dos jovens, no bojo de uma "tendência contemporânea de fracionar os segmentos portadores de direitos (a criança, o adolescente, a mulher, o idoso...)" (Carvalho, 1994, p. 46) e, embora representando um avanço indiscutivel na linha da defesa dos direitos e da dignidade da pessoa humana, provocaram uma focalização dos indivíduos em detrimento do grupo e da coletividade, relegando a um segundo plano as políticas e programas voltados à família, taxados, nesse momento, de conservadores (Draibe, 1994).

A retomada da família enquanto unidade de atenção, nos últimos anos, como forma de encontrar soluções mais eficazes para os problemas vividos pelos indivíduos, tem implicado na produção de uma multiplicidade de programas que, como afirma Sarti (1995), apesar das inovações em termos de conteúdo, têm se mostrado de difícil operacionalização, apresentando resultados pouco satisfatórios. Parece existir um "abismo" na linguagem existente entre os que oferecem e os que recebem os serviços, ou melhor, entre as necessidades vividas e as respostas oferecidas.
No caso específico das famílias pobres, pode-se dizer que estas são alvo de ações fragmentadas decorrentes de políticas que negligenciam a necessidade de compreender esse sistema no seu contexto e através de seus valores, correndo-se o risco de estigmatizá-las, do mesmo modo que se fez nos primeiros tempos da assistência social (Takashima, 1994). A orientação subjacente a esses programas, fornecida pela política social mais ampla, favorece a implementação de ações especiais para grupos de famílias considerados especiais, reforçando os processos de exclusão social já existentes. As famílias tidas "naturalmente" como disfuncionais é que são focalizadas pelos programas assistenciais (Rosemberg, 1994).

Como dizem Carvalho \& Guará (1994), no "contexto de uma cultura tutelar para com os empobrecidos, dominante em nosso país, as atenções para com a família são conservadoras e inerciais e reafirmam o signo da subalternidade com ajudas em espécie, eventuais e emergenciais, para mantê-las dependentes perpetuando o culto do 'favor' e não a garantia do direito" (p. 46).

$O$ ponto de partida para um trabalho acertado deveria ser, nas palavras de Szymanski (1994), "a compreensão, por parte do técnico (tanto os profissionais como o pessoal leigo que trabalha com as famílias), do próprio modelo de organização familiar, com as crenças, valores e procedimentos que efetivamente são adotados na sua vida em família ou aqueles que considera os 'melhores' ou os 'certos'. Igualmente importante é tomar conhecimento das experiências, teorias, influências envolvidas no processo de construção desse modelo" (p. 38).

Sem a pretensão de que isso explique todas as dificuldades para a implementação de programas de ajuda mais efetivos, considera-se que a existência de uma certa ignorância, por parte dos interventores, com relação ao universo sócio-cultural que circunda e constitui esses grupos familiares, é um ponto de grande entrave. Dentro desta perspectiva, é imprescindível conhecer melhor essa clientela, seus valores e sua dinâmica, visando aumentar a qualidade dos serviços a ela oferecidos.

É neste sentido que o presente trabalho pretende contribuir, realizando uma reflexão acerca das características de famílias geralmente visadas pelos serviços da assistência social, utilizando-se, para tan- 
to, de alguns dados referentes a histórias de vida; coletados junto a famílias de crianças e adolescentes considerados em situação de risco psicossocial, atendidas em um programa especial de proteção, do $\mathrm{Mu}$ nicípio de Ribeirão Preto - SP.

\section{Perspectiva teórica: Familias de classes popula- res}

Na intenção de caracterizar famílias de classes populares, vale destacar, num primeiro momento, a noção de classes populares.

Segundo Durham (1986), existe um rico e abundante material sobre o modo de vida destas classes. Apesar da grande diversidade presente entre os muitos grupos estudados sob esta classificação, evidenciam-se: a uniformidade dos dados relativos a valores fundamentais, hábitos, gostos e aspirações que caracterizam essa classe e a homogeneidade referente às formas de sociabilidade, representações e organização próprias à sua dinâmica (Romanelli, 1997).

De um modo geral, podem-se descrever estes segmentos da população em função das condições concretas de vida nas quais eles se situam: habitações precárias, ingressos monetários reduzidos (independentemente dele provir de uma inserção no mercado de trabalho formal ou informal), difícil acesso aos direitos sociais como saúde, educação, aposentadoria e saneamento básico (Agier, 1990; Durham, 1986). "De modo descritivo, a noção de classes populares tem sido utilizada para designar a população pobre dos centros urbanos, caracterizada pela precariedade de condições de vida que resultam não só da inserção dos trabalhadores nas relações de produção, mas de sua participação nas relações de distribuição, vale dizer, do montante de rendimentos auferidos" (Romanelli, 1997, p. 26).

Embora o indivíduo oriundo dessas classes possa habitar por toda parte nas grandes cidades, existe um lugar em que ele é preferencialmente encontrado, "um espaço que lhe é próprio e onde se constituí a expressão mais clara de seu modo de vida. É a chamada periferia" (Durham, 1986). Falar das periferias torna-se importante na medida em que os quilômetros que as separam "do centro", dos locais de trabalho e dos serviços públicos, aumentam a segregação e o isolamento vivido pela população pobre, favorecendo o desenvolvimento de uma sociabi- lidade local (Durham, 1986).

Neste cenário figuram as famílias das classes populares. Acredita-se que tais condições de vida definam ou orientem, em grande parte, a dinâmica, os projetos de vida e as estratégias de sobrevivência deste sistema nas camadas economicamente desprivilegiadas da sociedade.

A família é um elemento básico de organização do modo de vida nas classes populares e, embora existam variados arranjos, o modelo de família nuclear estável ainda predomina para estas camadas da população. "A permanência deste arranjo familiar traz inúmeras vantagens pois assegura a formação regular de rendimentos que viabilizam o consumo coletivo..." (Romanelli, 1997, p.26). Quando esse arranjo nuclear estável não é possível, o modelo permanece no imaginário das famílias como estrutura ideal, provocando um certo "mal-estar" em virtude da distância entre a "família pensada" e a "família vivida" (Carvalho \& Guará, 1994; Szymanski, 1992).

De qualquer modo, a família, enquanto grupo coeso, interessa especialmente às classes populares pois é através da colaboração entre seus membros que se garante a própria sobrevivência e buscase uma melhoria nas condições de vida, planejandose o futuro. Os esforços de cada indivíduo vão (ou devem ir) sempre na direção da realização do projeto coletivo.

Entre outros ideais que norteiam os projetos das famílias pobres, o desejo de construir a casa própria é central e está associado à própria idéia do casamento, da constituição de família. "Casar, ter uma casa e ter filhos é um projeto único" (Sarti, 1989). Neste sentido, vale lembrar que a procura por terrenos baratos, que viabilizem o projeto da casa, explica a ida e a fixação nas periferias dos grandes centros urbanos.

Entretanto, no seu percurso de vida, a família vai sendo marcada por acontecimentos previsíveis e imprevisíveis - inerentes ao seu próprio ciclo vital ou provenientes do domínio público - que concorrem para uma revisão e alteração dos projetos em comum (Romanelli, 1997). Para as familias de todas as classes sociais é difícil equilibrar ou conciliar os objetivos coletivos e as aspirações individuais, principalmente, na medida em que os filhos crescem, carregando a cena doméstica de tensões e conflitos (Salem, 1980). De forma peculiar, a pobreza, a pre-

Paidéia, FFCLRP-USP, Rib. Preto, jan/julho/2000. 
cariedade própria das classes populares, contribui para o esmorecimento de alguns dos membros da família com relação aos projetos de vida, uma vez que as economias vão sendo investidas em "urgências". Esta situação também tende a ampliar as áreas de tensão na cena doméstica (Romanelli, 1997).

\section{Maridos, Esposas e Filhos nas Classes Populares}

Considerando que as famílias, de um modo geral, estruturam-se a partir de relações de autoridade e poder, permeadas por afetos, onde as pessoas ocupam posições hierárquicas, com direitos e deveres específicos (Romanelli, 1997), é possível conceber o papel de cada membro do sistema familiar, homens-maridos, mulheres-esposas e crianças-filhos bem como as representações que se tem dos mesmos dentro de cada grupo, em função da classe social de origem.

De acordo com Sarti (1989), quanto mais árdua for a condição de vida e mais limitadas as possibilidades e os meios de sobrevivência do grupo familiar, mais rígida é a divisão de papéis e menor é o espaço para a individuação. Em linhas gerais, poderse-ia dizer que do homem-marido espera-se que seja o provedor, que ele dê conta de atender às necessidades básicas de sua família e que ele "cumpra" uma presença moral como marido e pai, conferindo respeitabilidade ao grupo doméstico (Agier, 1990; Sarti, 1989).

Para a população pobre, as representações a respeito de homem digno e respeitável associam-se diretamente à noção de trabalhador. Esta característica seria o eixo central na organização da identidade masculina, tanto no plano social, quanto no pessoal. "Porque é trabalhador, sujeito adequadamente inserido em uma ordem social estabelecida, pode realizar de modo satisfatório outros aspectos da identidade social...", como ser marido, pai e amigo, por exemplo (Romanelli, 1997, p. 32).

Para essas famílias, a importância do trabalho deve-se, de um lado, ao seu aspecto instrumental, uma vez que dele derivam os rendimentos, fundamental para a sobrevivência do grupo doméstico. Por outro lado, paira a representação de que o trabalho "enobrece", "dignifica", estabelecendo fronteiras simbólicas entre os trabalhadores e os ociosos (Romanelli, 1997; Sarti, 1989; Zaluar, 1985). Dentro desta perspectiva, pode-se compreender que cer- tos comportamentos como os de violência ou alcoolismo, por parte do homem, possam ser tolerados dentro da família, desde que ele "permaneça" trabalhador (Sarti, 1989). Os "vícios" só são combatidos quando, de algum modo, prejudicam o homem no desempenho de suas obrigações para com o lar (Zaluar, 1985).

Como na prática a atuação deste trabalhador gera resultados insatisfatórios, o traço, que $a$ priori é positivamente valorizado e sintetizador da identidade masculina, transforma-se, pouco a pouco, em elemento de cisão e fragmentação da imagem que o homem das classes populares tem de si mesmo (Romanelli, 1997). Segundo Agier (1990), o peso do significado simbólico do papel de marido, dentro das famílias pobres, é bastante pesado e explica, em boa parte, a instabilidade matrimonial para esses segmentos da população, tendo em vista os comportamentos de desistência, pânico e fuga, direta ou indiretamente decorrentes de um revés social.

Com relação às mulheres-esposas das classes populares, a expectativa de integrarem econômica e/ou profissionalmente a sociedade é pequena, pois a socialização, nesses segmentos, favorece seu desenvolvimento e atuação na esfera privada, o que se contrapõe à necessidade imperativa de fazê-lo para um número significativo delas (Agier, 1990). O elemento sintetizador da identidade pessoal e social para o homem é o trabalho, enquanto que para a mulher é a maternidade.

Além disso, a identidade feminina fundamenta-se igualmente na respeitabilidade de uma condição familiar estável, oriunda de uma união formal ou informal, e, neste sentido, ela depende do homem. A ausência do marido, pai de seus filhos, faz-se notar não apenas pela "falta do provedor, mas pela importância da figura masculina como garantia de uma imagem exterior de respeitabilidade da família" (Sarti, 1989).

O peso simbólico referente ao fato de ser mulher é, assim, de ordem moral ou doméstica. Ela é responsabilizada pelo bom funcionamento da casa, pelo estabelecimento das condições que manterão o marido no trabalho e pelo cuidado e bom comportamento dos filhos. "Dela depende a reprodução da família dentro de um padrão desejado de moralidade" (Sarti, 1989).

Os arranjos matrifocais, para essas mulhe- 
res, separadas ou abandonadas, assumem sempre um caráter provisório em virtude da esperança e das ações que elas empreendem para poderem atualizar o modelo de família nuclear e "ter um homem em casa". Enquanto esperam, essas mulheres buscam a presença mais ou menos contínua de outras figuras masculinas na cena doméstica, geralmente a elas ligadas por laços de consangüinidade. Essa atitude visa uma espécie de "apadrinhamento" para seus lares e, embora tal proteção ou ajuda nem sempre seja eficaz, caracteriza-se como uma das estratégias de sobrevivência feminina (Fonseca, 1987).

Apesar do apoio que eventualmente recebem na rede social onde estão inseridas, a ausência do marido ou companheiro obriga muitas mulheres a procurarem pela inserção no mercado de trabalho. Como elas não têm uma formação profissional, a possibilidade de empregos é pré-limitada e, geralmente, condiz com a execução de tarefas de cunho doméstico,pouco valorizadas no mercado de trabalho (Agier, 1990).

Obviamente, muitas mulheres das classes populares trabalham, mesmo estando casadas. Neste caso, suas atividades são consideradas apenas "uma ajuda". "A luta" para prover a família é vista como simbolicamente masculina. Na prática, entretanto, quando "a ajuda" da mulher assume uma dimensão muito grande, as relações de poder dentro do âmbito familiar podem se alterar, gerando conflitos (Romanelli, 1997).

No que diz respeito à criação dos filhos, as representações sobre a maternidade são de que a mãe deve ser "zelosa". Na prática cotidiana dessas famílias, entretanto, a necessidade de conciliar o cuidado da prole e uma série de atribuições, principalmente quando a mãe "trabalha pra fora", faz com que ela recorra a determinadas estratégias. Primeiramente, ela educa os filhos para tornarem-se aptos a cuidarem de si mesmos o mais rápido possível (Romanelli, 1997). Nesta linha, é preciso ressaltar que, desde muito cedo, os filhos das famílias pobres participam das obrigações familiares responsabilizando-se pela realização de pequenas tarefas ou trabalhos, seja na esfera doméstica ou na pública. Essa prática, além de percebida pelos pais e crianças como "formadora-educadora", é interpretada pelo prisma da equiidade na prestação de serviços e trocas que deve equilibrar e regularizar as relações entre os membros no sistema familiar (Dauster, 1991; Sarti, 1995). Assim, as crianças perdem suas regalias na medida em que estejam em condição de "trabalhar ou ajudar em casa", penetrando de forma mais ou menos abrupta no mundo dos adultos e do trabalho. Essa passagem caracteriza o que Ariès descreveu como "infância de curta duração" (apud Dauster, 1991).

Em segundo lugar, é possível que recorra à ajuda dos outros, promovendo "a circulação de crianças", procedimento em que o cuidado e a responsabilidade para com elas é coletivizada e inscrevemse na rede de relações e parentesco dos pobres (Sarti, 1995).

Não é raro, também, que em algumas situações de maior dificuldade ou precariedade, os filhos sejam confiados temporariamente a instituições de guarda (Sarti, 1995). Isso não significa um desapego materno mas sim um padrão pragmático-cultural que "permite uma solução conciliatória entre o valor da maternidade e as dificuldades concretas de criar os filhos..." (Sarti, 1995, p.9). É provável que tal prática favoreça o estabelecimento de uma forma de apego e de demonstração afetiva, diferentes dos padrões relacionais em que existe maior estabilidade nas interações entre os membros da família.

Assim, no que concerne às crianças de classes populares, pode-se imaginar que ao longo de suas vidas elas "circulem" entre diferentes unidades domésticas e ambientes diversos, interiorizando diferentes modelos de conduta, muitos deles, contraditórios e ambíguos (Romanelli, 1997; Sarti, 1995).

De forma geral, $e$ nesse contexto de condições precárias e de instabilidade, permeado por valores e significados próprios, relativos à infância e às práticas educativas, que a "criança pobre" se desenvolve e tem sua identidade estruturada.

Dentro desse panorama, estudar-se-ão as histórias de vida de famílias que, num dado momento, foram integradas a um programa específico de assistência social porque se considerou que as mesmas ofereciam risco ao desenvolvimento salutar de seus filhos.

\section{Metodologia}

Após revisão bibliográfica, procedeu-se à coleta de dados relativos a famílias visando a reconstituição de suas histórias de vida, centrandose em suas trajetórias até ou a partir do momento em 
que se viram ligadas ao programa de proteção destinado aos seus filhos, considerados em situação de risco psicossocial.

Para tanto, empreendeu-se uma análise dos documentos da instituição - os prontuários dos beneficiários - e a entrevistas com o coordenador do serviço, responsável direto pelo contato com as famílias, com vistas à recuperação de elementos do caminho percorrido pelas famílias, bem como estabeleceu-se um contato informal com as mesmas, através do qual também pode-se checar e obter algumas informações.

Vale notar que todas as famílias ligadas ao serviço em questão, no período da coleta, foram investigadas, ou seja, sete grupos familiares. Contudo, optou-se aqui por apresentar a historia de somente três delas, considerando que todas eram bastante semelhantes entre si, sendo, portanto, as três, representativas do grupo.

As histórias reconstituídas são aqui relatadas em torno de um eixo temporal inerente ao desenrolar dos acontecimentos. Contudo, é preciso enfatizar a existência de lacunas e de pequenas contradições espaço-temporais que impõem uma leitura parcimoniosa dos dados coletados. Estes certamente correspondem a uma descrição bastante parcial da realidade.

Os nomes empregados para descrever as familias são fictícios.

\section{I - A Familia Rosário}

Os cinco irmãos Rosário, cujas idades variam entre 10 e 13 anos, estão na instituição há seis anos e meio. A instituição fora acionada a fim de "recolher" as crianças que se encontravam "distribuídas" entre vizinhos e parentes em virtude do aprisionamento da mãe, por medidas judiciais. O pai, por sua vez, já estava preso há mais de um ano.

A ida das crianças para a instituição se deu com a aprovação da avó materna que, pouco antes da prisão da filha, responsabilizava-se pela maior parte dos cuidados dispensados às crianças.

Mesmo tendo ficado somente um mês na prisão, a mãe permitiu, e mesmo solicitou, após sua soltura, que as crianças permanecessem na instituição, alegando que seu grande envolvimento com drogas e atos infracionais eram prejudiciais aos filhos.

Nesta época, a mãe fora enviada, com o auxílio dos técnicos da instituição, para uma clínica de desintoxicação, situada em outro município.

Eventualmente, as crianças iam visitar os familiares na casa dos avós maternos, habitada por outros componentes da família, além do casal (filhos, filhas, netos e parentes). Os familiares paternos, embora morando nas proximidades, nunca se envolveram neste processo de institucionalização das crianças.

Ao sair da clínica de "recuperação", a mãe volta, quase que imediatamente, ao consumo das drogas. Ela se instala em um barraco da favela, próxima à casa materna. Neste período, ela vive da renda proveniente de atividades ilegais, tais como tráfico e pequenos furtos. Alguns meses mais tarde, devendo desfazer-se do barraco por causa de dívidas de drogas, ela começa a morar "ora ali, ora acolá", instalando-se junto a novos companheiros. Dessa forma, tem início um processo de separação afetiva do marido, ainda prisioneiro. Até então, ela o visitava de forma mais ou menos regular.

Com relação aos filhos, o contato, durante este período, fora bastante esporádico e dependia da uma iniciativa da instituição para procurá-la a fim de levá-los para visita. Somente a avó materna mantivera um contato mais assíduo com as crianças, recebendo suas visitas, indo até a instituição para visitálas ou telefonando.

Neste período, uma das crianças fora adotada legalmente por uma ex-funcionária da instituição, tendo a mãe e a avó materna concordado inteiramente com o processo.

No ano seguinte, o pai é libertado da prisão e retoma contato com as crianças, porém de forma bastante irregular. Este só as visita esporadicamente na instituição, sem levá-las para sua nova residência, cujo endereço, aliás, permanece desconhecido dos técnicos da instituição.

Aproximadamente um ano depois, o pai "desaparece" por vários meses. Ao reaparecer, comunica estar indo para outro estado do país, para trabalhar. Durante dois anos ele aparece duas vezes na instituição para visitar os filhos.

Neste ínterim, a mãe descobre ser portadora do vírus HIV. Com a ajuda da instituição, passa um período numa clínica de saúde para receber tratamento. Por algum tempo ela procura uma maior proximidade com os filhos, visitando-os e recebendo-os 
na casa de sua mãe. Contudo, alguns meses depois; ela desliga-se voluntariamente da clínica e volta a se drogar, tornando sua presença junto aos filhos novamente irregular.

Originalmente, esta família veio do norte do país para se instalar em Ribeirão Preto na procura de melhores condições de vida. A mãe, segundo o relato de terceiros, era "boa mãe e trabalhadeira e fazia faxina para fora". O pai era pedreiro.

\section{II - A Familia Mendonça}

Os três filhos Mendonça, cujas idades variam entre 10 e 16 anos, foram acolhidos na instituição há seis anos, tendo sido encaminhados pelo Juiz da Infância e Juventude, por medida de proteção, porque a mãe encontrava-se sob ameaça de morte na favela em que moravam. Ela havia denunciado algumas pessoas para a polícia, alegando que estas haviam roubado seu barraco.

Nesta ocasião, marido e mulher já haviam se separado e, embora o pai morasse nos arredores da casa da ex-esposa, este não mantinha contato algum com os filhos. Ele alcoolizava-se constantemente.

Alguns dias depois das crianças terem ido para a instituição, o barraco da mãe fora incendiado e esta sofrera algumas agressões físicas, devendo, portanto, mudar-se de lá. Neste sentido, deu-se à mãe, que na época trabalhava em uma pensão, o prazo de 3 meses para se reorganizar e reassumir os cuidados dos filhos, recebendo, para tanto, ajuda da instituição para a aquisição de móveis e utensílios domésticos. Entretanto, na seqüência, a mãe desaparecera completamente, sem deixar qualquer endereço. Durante este período, as crianças nunca foram visitadas por outros familiares pois, segundo informações de terceiros, a mãe teria rompido relações com sua própria família de origem.

Cinco meses mais tarde, a instituição descobriu que a mãe alojara-se em outro bairro da cidade e coabitava com um novo companheiro. Ao ser contatada, esta teria dito não se sentir em condições de reassumir os filhos naquele momento por estar doente e pelo fato de a casa ocupada ser muito pequena.

Alguns meses depois, ela teria sido beneficiada por um programa de desfavelamento, obtendo uma casa num outro bairro. Por esta ocasião, ela reassume a guarda do garoto mais velho, resistindo, contudo, a receber os outros dois filhos. No mesmo período, engravida e dá à luz uma menina, fruto da nova relação. Os rendimentos familiares, nesta época, provêm de "bicos" feitos pela mesma e pelo companheiro em campanhas eleitorais.

A instituição começa então a negociar a volta das duas crianças mais novas para a casa. Porém, neste momento, fica-se sabendo que a mãe perde a casa pois a mesma é vendida pelo companheiro que desaparece com o dinheiro. Desta forma, adia-se mais uma vez o retorno das crianças ao convívio familiar porque a mãe passa a morar de favor na casa de amigos e vizinhos.

Algum tempo depois, ela reata com o companheiro que reaparece. Ele teria então recebido uma proposta de trabalho em uma firma, com a possibilidade de morar no próprio emprego. Moraram lá por volta de um ano e meio sem, contudo, receberem definitivamente as crianças que permaneceram institucionalizadas todo esse tempo. Segundo a mãe, a casa seria muito pequena para acolhê-las bem.

Após esse período de maior estabilidade em termos de moradia, a mãe é novamente despejada porque seu companheiro teria efetuado um furto dentro da firma que o empregara.

Mais uma vez, a mãe passa a morar de favor na casa de amigos e, depois de conseguir um emprego como cozinheira, em um buffet, aluga uma edícula nos fundos de uma casa, num bairro bastante distante da instituição. Tendo em vista esta condição, a instituição procura promover a reintegração dos dois filhos junto à mãe, mas, até o momento, esta diz não se sentir preparada, dada a instabilidade de seu atual emprego.

\section{III - A Familia Salgado}

Três crianças da família Salgado foram encaminhadas à instituição em virtude de denúncias feitas pela comunidade, porque a mãe havia morrido e elas, apesar da pouca idade, moravam sozinhas em uma casa invadida, em condições insalubres. Segundo informações de vizinhos, elas mendigavam, furtavam e faziam uso de droga "para viver", mesmo antes da morte da mãe. Esta, por sua vez, teria morrido de overdose, quatro meses antes.

Anteriormente, contudo, a família teria sido constituída por união estável entre o pai, a mãe e 
quatro filhos.

Do que se sabe, o pai sempre teria obtido seus rendimentos do envolvimento com o tráfico de drogas, tendo sido assassinado por um rival, aproximadamente um ano antes. A mãe teria sido faxineira num período anterior ao uso abusivo de drogas.

A quarta e última criança, uma menina, teria sido levada para trabalhar em outra cidade, logo após a morte do pai, por uma senhora (para quem a mãe já trabalhara), tendo perdido completamente $o$ contato com a família de origem, antes mesmo do falecimento da mãe.

Após algumas idas e vindas entre a instituição em questão, outros serviços ribeirão-pretanos e famílias substitutas, o filho mais velho, um adolescente, beirando os 18 anos, estaria vivendo na rua $e$ consumindo drogas de forma abusiva, sendo que os outros dois filhos, com 13 e 17 anos, foram acolhidos no Abrigo de forma definitiva, estando lá há aproximadamente um ano e meio.

Em termos de parentesco, sabe-se que esses jovens possuem alguns primos instalados na cidade. Contudo, alguns se encontrariam presos e outros estariam trabalhando na zona rural, nos arredores do Município. O contato entre eles é praticamente inexistente.

\section{Discussão}

As histórias aqui descritas, embora permitam reconhecer elementos que caracterizam as famílias de classes populares em geral, a sociabilidade e a dinâmica que lhes são inerentes, retratam situações limítrofes em termos de condições de sobrevivência econômica e de manutenção do agregado familiar.

É importante notar que as três famílias partem, originalmente, de um modelo nuclear, onde a união entre o homem e a mulher gera filhos e, muito provavelmente, sonhos de melhoria das condições de vida. Ao longo do tempo, verificar-se-iam transformações nesses ideais e, nestes casos específicos, a desagregação do grupo inicial.

Pode-se inferir, com base no que diz Durham (1986), que os projetos e ideais dessas famílias, sempre pensados como sendo de iniciativa e responsabilidade do indivíduo, começa a pesar sobre a estrutura da mesma na medida em que as condições "dadas" socialmente dificultam enormemente, chegando a impedir, a realização da maioria dos so- nhos. "A crise econômica com seus corolários de desemprego, diminuição da renda familiar e aumento do custo de vida desestrutura todo o esquema em função do qual as classes populares 'organizam' sua prática social..." (Durham, 1986, p. 57).

No que diz respeito aos homens citados nessas histórias, as dificuldades por eles enfrentadas a fim de se inserirem no mercado de trabalho, de obterem os rendimentos necessários e, mesmo, a fim de preservarem suas identidades "de provedores/chefes de família", teriam feito eles viverem o fracasso num plano individual.

É possivel aventar que tais vivências os teriam conduzido a comportamentos de pânico ou fuga (Agier, 1990), explicando, em parte o alcoolismo do pai biológico da família II.

No que se refere aos homens das outras duas famílias, o mesmo quadro poderia tê-los conduzido a "soluções alternativas" (atos infracionais) visando manter a própria integridade e a integridade da família. Este dado é bastante condizente com a "ética do provedor", discutida por Zaluar (1985). Segundo a autora, frente ao processo de aviltamento socioeconômico, o valor moral do trabalho desvincula-se da atividade propriamente dita ("ética do trabalho") para ligar-se ao fato dele garantir o "ganha-pão" da família ("ética do provedor"). $\mathrm{Na}$ medida em que a degradação salarial impede que os homens garantam a sobrevivência, o constrangimento de passar a "bandido" pode ser menor que o de ver o grupo doméstico "passar fome ou vontade". Ademais, se a virilidade e a autoridade do homem apóiam-se no poder que ele desfruta na hierarquia social e familiar, por que não imaginar que a criminalidade, de algum modo, recupera e integra esses elementos de uma maneira bastante eficiente?

De qualquer modo, é provável que esses homens experimentem, em alguma medida, pessoal e socialmente, as (auto) acusações por terem "se desviado do ethos do trabalho, da imagem de homem honesto e trabalhador"' (Sarti, 1989).

Como conseqüência, na biografia das três famílias existe um período em que as mulheres vêemse sozinhas, com seus filhos ainda pequenos, devendo assumir integralmente as responsabilidades. Segundo Romanelli (1997), estas famílias (temporariamente matrifocais) tornar-se-iam as mais vulneráveis. Ao mesmo tempo em que estariam vivendo a primei- 
ra fase de seus ciclos vitais, quando seus filhos ainda exigem maiores cuidados, os rendimentos oriundos dos maridos tornar-se-iam inexistentes e de difícil substituição.

É patente que todas as mães citadas tentaram, num momento ou noutro, uma inserção no mercado de trabalho e o fizeram através da mercantilização de tarefas domésticas (Agier, 1990), dada a falta de preparo ou especialização para desempenharem atividades melhor remuneradas. Neste sentido, pode-se calcular a insuficiência de rendimentos auferidos com a intenção de manter a unidade familiar.

Levando-se em consideração que para a auto-imagem dessas mulheres os elementos fundamentais referem-se ao sentimento de serem "boas mães" e "de terem seus maridos, não só ao lado, mas trabalhando", é possível imaginar que as mesmas tivessem começado a sofrer um processo de dupla per$\mathrm{da}$ em termos de identidade pessoal e social. A situação se desequilibra tanto no domínio privado quanto no público.

De acordo com a literatura, impõe-se, neste momento, o "acionamento da rede de vizinhos e parentes" e a "circulação de crianças" como estratégias de sobrevivência dessas famílias. Contudo, principalmente para as famílias II e III, em virtude do aparente isolamento vivido com relação a parentes e vizinhos, o recurso à institucionalização parece tornar-se uma solução plausível para os problemas enfrentados no momento.

No caso da família I, notar-se-ia, à priori, a efetivação da rede de parentes e amigos com o intuito de dividir o peso das dificuldades e responsabilidades. Contudo, se se pensa em termos de "sentimento de fracasso" para a mãe, é importante lembrar a presença marcante da avó materna das crianças, que passa a assumir muitas das decisões e responsabilidades maternais. Esse mecanismo, comum em muitas famílias de classes populares (Sarti, 1995), diminuiria gradativamente a importância da mãe biológica no cenário familiar, encorajando sua "má conduta" e explicando-se através dela.

De qualquer modo, o envio dos filhos para uma instituição de guarda é concebido e aceito como medida conciliatória entre a maternidade (os cuidados que a criança precisa receber) e as duras condições de vida. Entretanto, pode-se supor, em tais ca- sos, o quanto tal prática não favorece a concretização de sentimentos de fracasso enquanto mulher e mãe, suscitando, no caso feminino, a sensação de desvio em relação ao ethos familiar.

Mais especificamente com relação à família II, vale lembrar que, além da ida dos filhos para a instituição enquanto garantia de sobrevivência, a permanência prolongada dos mesmos na instituição de abrigo poderia estar se relacionando com o novo arranjo familiar estabelecido pela mãe, com outro companheiro, e a filha oriunda desta relação. O distanciamento desta mulher em relação aos filhos da primeira união pode ser interpretado como investimento necessário para o estabelecimento de um novo relacionamento, tendo em vista a possibilidade de recriar a família nuclear, e não necessariamente em função de um desapego materno-filial crescente (Fonseca, 1987).

De outro lado, tem-se um homem (o novo companheiro) que, face aos filhos da mulher com outro, pode se sentir ameaçado em sua masculinidade, reagindo à situação de modo a dificultar a volta dessas crianças ao lar.

Cumpre, entretanto, lembrar que somente o filho mais velho da família II é reintegrado ao novo núcleo doméstico talvez porque, com a sua idade girando em torno dos 15 ou 16 anos, os adultos vislumbrariam a possibilidade de sua inserção no mercado de trabalho. Neste caso, o fato de ele poder contribuir com o orçamento do grupo prevaleceria, em detrimento dos possíveis sentimentos de rejeição do padrasto, ao passo que as crianças mais jovens ainda significariam um peso, em termos de custo e benefício, para a dinâmica familiar.

De qualquer modo, se se postula a existência de uma "família idealizada" em relação a uma "vivida", a distância entre ambas, para todos os casos descritos, parece ir se ampliando ao longo de suas trajetórias, aumentando possivelmente também o "mal-estar" vivido por cada membro constituinte do núcleo familiar.

Sem a pretensão de concluir uma análise sobre as histórias das famílias aqui apresentadas, sobretudo ante a escassez dos dados, fica a certeza da complexidade do assunto e da enormidade de variáveis a serem consideradas.

É preciso ressaltar a importância de compreender as famílias a partir de seus pontos de vista e 
das condições concretas e subjetivas que as circundam, evitando julgamentos de valor quanto a padrões de comportamento. A ênfase nos aspectos subjetivos, inerentes às suas vivências, é fundamental à superação de um modelo reducionista para as abordagens que tendem a considerar as classes populares somente em suas necessidades materiais (Carvalho \& Guará, 1994).

Enxergar o grupo somente através de suas dificuldades aparentes (o alcoolismo, a drogadição, o envolvimento com o crime, o "abandono" ou distanciamento dos filhos, bem como a freqüente busca por novos companheiros, no caso das mulheres) geralmente tomadas como o problema em si, contribui para visões que tendem a culpabilizá-lo e/ ou criminalizar seus comportamentos que, por sua vez, naturalizam o movimento de afastamento puro e simples das crianças de seu meio de origem, para institucionalizá-las durante um longo período, impondo aos adultos a necessidade de mudarem sua conduta.

A compreensão dessas dificuldades, enquanto sinais da fragilização extrema de grupos familiares, vivendo em condições limites de precariedade material, social e emocional, poderia orientar a elaboração e a implementação de abordagens mais humanistas, capazes de levar em conta a dignidade de todos, sem perder de vista, logicamente, a importância de proteger a criança e o adolescente em seus diretos básicos, incluindo a convivência familiar e a comunitária.

\section{Referências Bibliográficas}

Agier, M. (1990). O sexo da pobreza: homens, mulheres e famílias numa "avenida" em Salvador da Bahia. Tempo Social, 2(2), 35-60.

Barreira, M.C.R.N.; Blanes, D.N. \& Carvalho, M.C.B. (1992). Trabalhando Conselhos Tutelares. Cadernos de Ação nº 2: CBIA/SP \& IEEPUC/SP

Carvalho, M.C.B. (1994). Serviços de Proteção Familiar. Cadernos de Ação n ${ }^{\circ}$ 5: CBIA/SP \& IEEPUC/SP.

Carvalho, M.C.B. \& Guará, I.M.F.R. (1994). A família: um sujeito pouco refletido no movimento de luta pelos direitos da criança e do adolescente. Revista Brasileira do Crescimento e do De- senvolvimento Humano, 4(1), 45-48.

Dauster, T. (1991). Uma infância de curta duração: o significado simbólico do trabalho e da escola e a construção social do "fracasso escolar" nas camadas populares. Departamento de Educação, PUC: Rio de Janeiro, mimeo.

Draibe, S.M. (1994). Por um reforço da proteção à família: contribuição à reforma dos programas de assistência social no Brasil. Em: S.M. Kaloustian (Org.), Família brasileira: $A$ base de tudo (pp.109-130), São Paulo: Cortez/UNICEF.

Durham, E.R. (1986). A sociedade vista da periferia. Revista Brasileira de Ciências Sociais, 1(1), 5899.

Estatuto da Criança e do Adolescente, Lei $n^{\circ} 8.069$. de 13 de julho de 1990.

Fonseca, C. (1987). Aliados e rivais na família. Re vista Brasileira de Ciências Sociais, v.2 (4), 88102.

Guirado, M. (1980). A criança e a FEBEM. São Paulo: Perspectiva.

Marcílio, M.L. (1998). História social da criança abandonada. São Paulo: Hucitec.

Romanelli, G. (1997). Famílias de classes populares: socialização e identidade masculina. Cadernos de Pesquisa - NEP, N. 1 e 2, 25-34.

Rosemberg, F. (1994). Crianças pobres e famílias em risco: as armadilhas de um discurso. Revista Brasileira do Crescimento e do Desenvolvimento Humano, 4(1), 28-33.

Salem, T. (1980). Conflito, poder e negociação na família: a questão geracional. Revista de Ciências Sociais, 23(2), 185-200.

Sarti, C.A. (1989). Reciprocidade e hierarquia: relações de gênero na periferia de São Paulo. Cadernos de Pesquisa, N. 70, 38-46.

Sarti, C.A. (1995). A continuidade entre a casa e a rua no mundo da criança pobre. Trabalho apresentado na XIX Reunião Anual da ANPOCS, mimeo.

Silva, R. da (1997). Os filhos do governo. São Paulo: Ática.

Szymanski, H.G. (1992). Trabalhando com as familias. Cadernos de Educação n 1 : CBIA/SP \& IEEPUC/SP. 
Szymanski, H.G. (1994). Educação para família: umà proposta de trabalho preventivo. Revista Brasileira do Crescimento e do Desenvolvimento $\mathrm{Hu}$ mano, 4(1), 34-39.

Takashima, G.M.K. (1994). O desafio da política de atendimento à família: dar vida às leis uma questão de postura. Em: S.M. Kaloustian (Org.), Familia brasileira: A base de tudo (pp.77-92), São Paulo: Cortez/UNICEF.

Zaluar, A. (1985). Os trabalhadores em suas famílias: trabalho e pobreza. Em: A. Zaluar (Org.), $A$ máquina e a revolta (pp. 87-131). São Paulo: Brasilense. 